\title{
Recorregut de recerca geològica i mineralògica per les comarques del Baix Camp i de la Conca de Barberà: des de Prades a Vilanova de Prades, Vallclara i a Vimbodí
}

Josep Maria Mata-Perelló

Joaquim Sanz Balagué

\section{XARAGALL \\ REVISTA DE CIÈNCIES DE LA CATALUNYA CENTRAL}

n. 4

ABRIL 2015 


\title{
RECORREGUT DE RECERCA GEOLÒGICA I MINERALÒGICA PER LES COMARQUES DEL BAIX CAMP I DE LA CONCA DE BARBERÀ: DES DE PRADES A VILANOVA DE PRADES, VALLCLARA I A VIMBODÍ
}

\author{
Josep Maria Mata-Perelló \\ Museu de geologia Valentí Masachs, Escola Politècnica Superior d'Enginyeria de Manresa \\ (EPSEM), Universitat Politècnica de Catalunya - BarcelonaTech (UPC), 08272 Manresa, Spain
}

\section{Joaquim Sanz Balagué}

Departament d'Enginyeria Minera i Recursos Naturals (EMRN), Escola Politècnica Superior d'Enginyeria de Manresa (EPSEM), Universitat Politècnica de Catalunya . BarcelonaTech (UPC), 08272 Manresa, Spain

Paraules clau: Sistema Mediterrani, Depressió Geològica de I’Ebre, Patrimoni miner

\begin{abstract}
Resum
Itinerari realitzat el 30 de maig de 2014. En aquesta ocasió, el recorregut de l'itinerari discorrerà, per la zona de contacte entre el Sistema Mediterrani (més concretament per la Serralada Prelitoral Catalana) i la Depressió Geològica de l'Ebre (pel seu sector corresponent a la Depressió Central).
\end{abstract}

Així, el recorregut śiniciarà a la primera unitat geològica, per on es farà la primera aturada, prop de Vilanova de Prades. Tot seguit, s'entrarà a la Depressió Geològica de I'Ebre, per la qual es circularà fins a la fi del recorregut, a la població de Vimbodí. Tot i això, en bona part del recorregut es transitarà prop de la Serralada Prelitoral Catalana, fins al punt de tornar a entrar en aquesta unitat, per tal de fer una parada a la Mina Saldes. Després i fins a la fi del recorregut, ja es tornarà a circular per la Depressió Geològica de l'Ebre, que ja no s'abandonarà, fins arribar a Vimbodí.

Per altra banda, la totalitat del recorregut s'haurà desenvolupat per la Regió de Reus, iniciantse a la comarca del Baix Camp (prop de Prades, tot i que no es farà cap aturada) per a continuar i finalitzar dintre de la Conca de Barberà (per on es circularà entre Vilanova de Prades i Vimbodí). 


\section{Objectius fonamentals}

Els objectius fonamentals que es pretenen aconseguir en aquest itinerari, es poden concretar en els següents aspectes generals:

1. Estudi i observació de la Serralada Prelitoral Catalana (integrada dintre del Sistema Mediterrani), per la qual discorrerà el recorregut de l'itinerari entre les poblacions de Prades (Baix Camp) i Vilanova de Prades (Conca de Barberà), a l'inici de l'itinerari. També, es tornarà a circular per aquesta unitat geològica, per les immediacions de la Mina Saldes (situada dintre del terme de Vallclara, a la Conca de Barberà) quasi a la fi del recorregut.

2. Reconeixement dels materials paleozoics (amb esquistos, pissarres i quarsites del Carbonífer; així com afloraments de granits, granodiorites i diorites). Aquests materials constitueixen exclusivament la Serralada Prelitoral Catalana, pels indrets del recorregut de I'itinerari, que hem esmentat abans.

3. Estudi i observació de la Depressió Central Catalana (la qual forma part de la Depressió Geològica de l'Ebre). Aquesta unitat geològica, l'anirem veient pels voltants de Vilanova de Prades, Vallclara i Vimbodí..

4. Observació i descripció dels materials terciaris (del paleogen), i dels quaternaris que sovint els cobreixen. Uns i altres reblen la Depressió Geològica de l'Ebre, tot formant el Complex $d^{\prime}$ Ulldemolins (pel que fa als cenozoics). Tanmateix, trobarem importants afloraments detrítics del Complex Montsant. Tots aquests materials s'aniran trobant a diferents indrets del recorregut de l'itinerari.

5. Observació de les estructures locals d'aquests materials, al llarg del recorregut de I'itinerari, i del contacte entre la Serralada Prelitoral Catalana i la Depressió Geològica de l'Ebre; i més concretament entre la vorera septentrional de la Taula de Prades, la Serra de la Llena i el Montsant.

6. Observació i reconeixement de diferents mineralitzacions situades a diferents indrets del recorregut de l'itinerari, d'acord amb l'ordre del seu recorregut,

6A) les mineralitzacions filonianes de $\mathrm{SiO}_{2}-\mathrm{Cu}$, encaixades entre materials granítics de la Serralada Prelitoral Catalana, que trobarem prop de Vilanova de Prades (Conca de Barberà).

6B) i les mineralitzacions filonianes de $P b-Z n$, que trobarem a la Mina Saldes, (a Vallclara, conca de Barberà) encaixades entre els materials del Carbonífer de la Serralada Prelitoral Catalana

7. Visió de les diferents explotacions dels georrecuros situats al llarg del recorregut de I'itinerari, relacionades amb les explotacions de les diferents mineralitzacions esmentades a l'apartat anterior.

8. Observació de les tasques de restauració dutes a terme sobre les explotacions anteriors, per tal de reduir l'impacte ambiental de les mateixes. O si s'escau de les restauracions espontànies produïdes.

9. Observació dels indrets relacionats amb el nostre Patrimoni Geològic i Miner, que trobarem al llarg del recorregut de l'itinerari. 


\section{Antecedents}

Pel que fa al recorregut del present itinerari, existeixen uns antecedents nostres, de tipus bibliogràfic referents a la totalitat del recorregut del mateix. Es tracta de MATA-PERELLÓ (1996, 1997, 1999, 2000, 2001, 2002, 2004, 2011, 2012a i 2012b); i també cal fer esment de MATA-PERELLÓ i COLLDEFORNS (1996).

Pel que fa a la descripció de les mineralitzacions d'aquesta comarca, cal parlar dels treballs de MATA-PERELLÓ (1991), relatiu a les mineralitzacions catalanes en general; i també dels de MELGAREJO (1992), centrat en els materials i les mineralitzacions del paleozoic, de les comarques del Baix Camp, de la Conca de Barberà i del Priorat

Per altra banda, i pel que fa a les característiques dels materials geològics, farem esment de dos treballs; concretament de: GUIMERÀ et altri (1982) i de RIBA et altri (1976). Tanmateix farem esment dels treballs de I'IGME (1973a i 1973b).

Tots aquests treballs referenciats, i d'altres, figuren esmentats per ordre alfabètic a l'apartat dedicat a la BIBLIOGRAFIA.

\section{Recorregut de l'itinerari}

El recorregut del present itinerari s'iniciarà a la localitat de Prades (a la comarca del Baix Camp). Des d'aquí, s'anirà cap Vilanova de Prades, realitzant-se una parada abans d'arribarhi. Així s' haurà entrat a la comarca de la Conca de Barberà, utilitzant les carreteres locals T 700 i TV -7005.

Seguidament, l'itinerari es dirigirà cap a les poblacions de Vallclara i de Vimbodí, utilitzant la carretera local TV - 7004. En aquest tram s' efectuaran les dos darreres aturades del recorregut d'aquest itinerari. Tot i així, abans d'arribar a la darrera població esmentada, es farà una fillola per un camí de forest, per tal d'arribar fins a la Mina Saldes, per on es farà una de les aturades del recorregut de l'itinerari. Finalment, aquest clourà en arribar a la darrera població esmentada.

\section{Advertiments previs}

Com en altres recorreguts de RECERCA GEOLÒGICA I MINERALÒGICA... si es disposa del temps suficient, poden efectuar-se passant per totes les parades i filloles. En cas contrari, recomanem prescindir de les anomenades PARADES - CONDICIONALS.

Per altra banda, alhora de fer el recorregut de l'itinerari, cal cercar abans tota la informació necessària, per tal de conèixer l'estat dels vials per on s'haurà de circular als diferents trams del recorregut de l'itinerari. En aquest recorregut, és cas de l'accés a la Mina Saldes de Vallclara.

Cal tenir una cura molt especial de respecte a la natura, al llarg de tot el recorregut; de l'itinerari. 


\section{Descripció de l'itinerari}

Com en altres itineraris, aquest s'estructurarà en una sèrie de PARADES o d'ESTACIONS que anirem veient a continuació. continuació. En cada una d'aquests aturades es farà un breu comentari. Per d'altra banda, darrera del nom de l'indret situarem (entre parèntesi) el número del full del Mapa Topogràfic, a escala 1:50.000, on es troba situat.

En aquest itinerari, utilitzarem els següents fulls: $\mathbf{4 1 7}$ (o de l'Espluga de Francolí) i $\mathbf{4 4 5}$ (o de Cornudella).

A continuació, començarem la descripció de les diferents aturades que formen part del present recorregut.

\subsection{Parada 1. CARRETERA DE PRADES A VILANOVA DE PRADES (TV - 7005), IMMEDIACIONS DEL SEU Km 1, (terme de Vilanova de Prades, comarca de la Conca de Barberà). (Full 417).}

El recorregut de l'itinerari, l'iniciarem a la població de Prades (dintre de la comarca del Baix Camp). Així, agafarem primer la carretera T - 700 (que condueix a Poblet), fins trobar la cruïlla amb la carretera TV - 7005. Aquesta cruillla la trobarem a uns $4 \mathrm{Km}$ de prades. En trobar aquesta cruillla, continuarem per aquesta carretera, anant cap a Vilanova de Prades. A menys de $1 \mathrm{Km}$ abans d'arribar a aquest poble, farem la primera aturada. Així, haurem recorregut uns 7'5 Km. En aquest trajecte, haurem entrat a la comarca de la Conca de Barberà.

En aquest recorregut, hem estat circulant en tot moment per la Serralada Prelitoral Catalana. Així, haurem trobat afloraments dels materials esquistosos paleozoics; tot i que fonamentalment haurem trobat granits i granodiorites, també del Carbonífer, com els anteriors. Aquestes roques són les que apareixen a l'indret de l'aturada, trobant-se molt alterats.

Entre aquests materials es fa clarament palès un filonet, amb mineralització de coure. Així es fa palesa la presència de CALCOPITITA, alterada a ATZURITA, MALAQUITA i a CRISOCOL.LA. Aquest filonet es fa molt palès a la part alta d'una antiga pedrera. (fotografia 1).

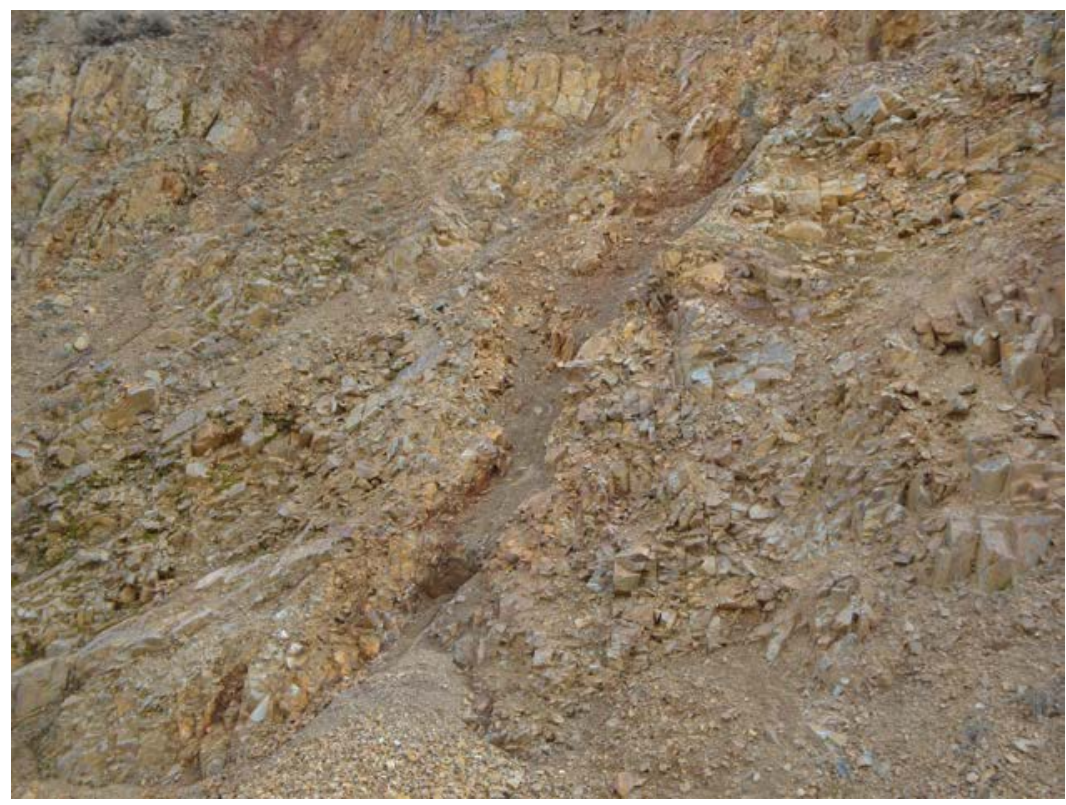

Fotografia 1. Restes del filó 
Des d'aquest indret, mirant cap al NE, es fa clarament palesa la Depressió Geològica de I'Ebre. Tanmateix es fa palès el contacte entre aquesta i la Serralada Prelitoral Catalana (on ens trobem ara situats). Aquest contacte es fa molt evident al sector septentrional del Pic Saldes; cal dir que en aquest indret es realitza per falla entre els materials carbonífers i els cenozoics de la Formació Morera de Montsant (amb passades de conglomerats). Per d'altra banda, en aquest indret es poden veure els afloraments dels nivells groguencs del Complex Lacustre del Montsant. Igualment, es poden veure els materials detrítics que constitueixen la Serra de la Llena: Cap a ponent, aquesta enllaça amb el proper Montsant. (fotografia 2).

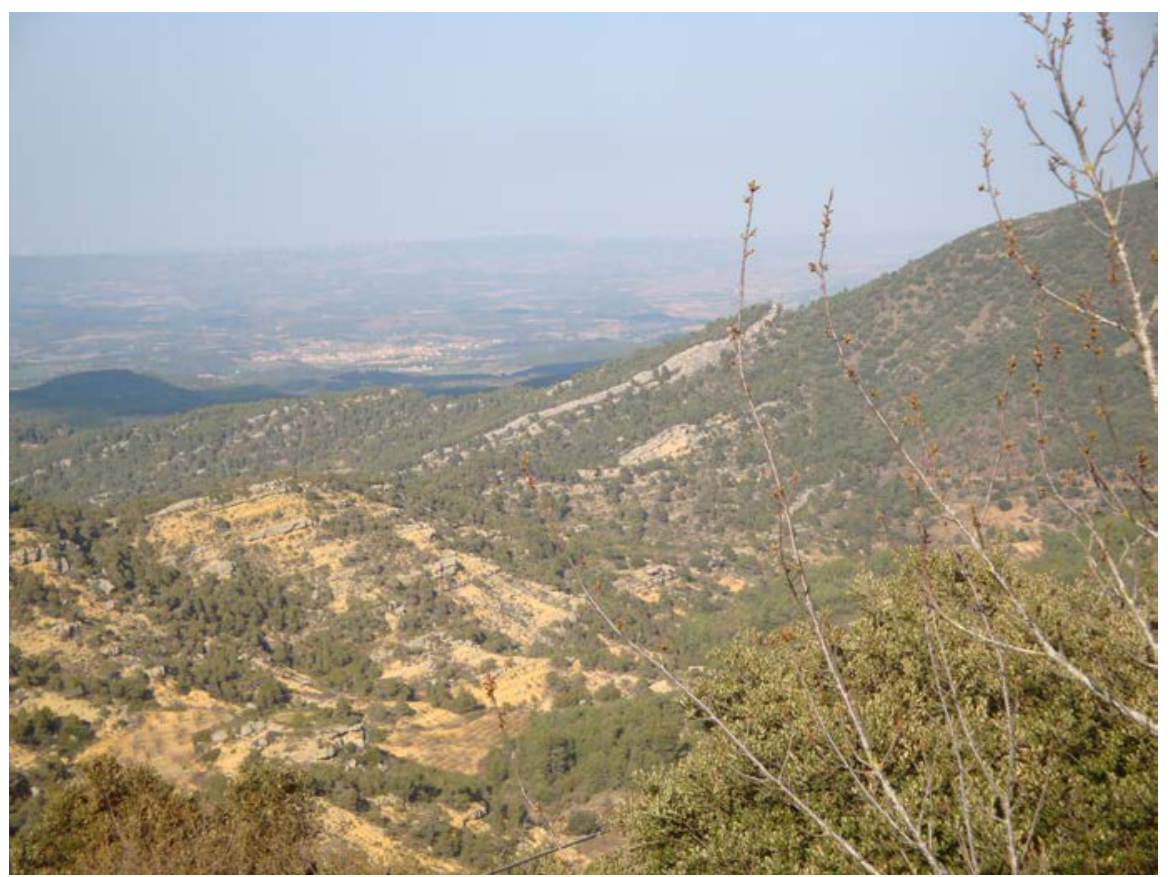

Fotografia 2. Contacte entre la Depressió Geològica de l’Ebre (a l'esquerra) i la Serralada Prelitoral Catalana (a la dreta)

\subsection{Parada 2. CARRETERA DE VILANOVA DE PRADES A VIMBODÍ (TV - 7004), INMEDIACIONS DEL Km 11, (terme municipal de Vilanova de Prades, comarca de la Conca de Barberà). (Full 417).}

Des de la parada anterior, cal continuar per la carretera local TV-7005, amb la finalitat d'arribar fins a l'immediat poble de Vilanova de Prades. Desprès, des de la sortida del poble, cal agafar la carretera local TV - 7004 (procedent d'Ulldemolins), per tal de continuar el recorregut cap a Vallclara i cap a Vimbodí. Més endavant, en arribar a les immediacions del Km 11, a uns $4 \mathrm{Km}$ de Vilanova i a uns 5 de la parada anteriorment efectuada, en caldrà fer una altra a la bora de la carretera.

En aquest recorregut, hem anat trobant afloraments dels materials del Complex Montsant (en concret de la Formació Montsant); així, haurem vist nivells de gresos i calcolutites groguenques; i també nivells de conglomerats. Aquests són els materials que apareixen prop de l'indret de la present aturada per on es fan evidents freqüents paleocanals, entre aquests materials cenozoics. 
Des d'aquest indret, situat sota de la Tossa (Serra de la Llena), es pot observar cap a l'ESE, a uns $500 \mathrm{~m}$ de la carretera, el contacte estructural entre els materials cenozoics de la Depressió Geològica de l'Ebre, i els paleozoics de la Serralada Prelitoral. Aquests materials paleozoics pertanyen al Carbonífer i presenten freqüents intrusions granítiques. Cal dir que aquests materials carbonífers, a l'àrea que ara visionem, es troben constituïts per nivells esquistosos $i$ quarsítics, fonamentalment. Per la seva banda, els materials terciaris estan constituïts per nivells de calcàries grises i de calcolutites ocres, que pertanyen possiblement a la Formació Morera de Montsant. Sobre aquests materials es troben els nivells de conglomerats i de gresos de la Formació Margalef. Per sobre d'ells, es troben els nivells dels conglomerats de la Formació Montsant, que formen els relleus de la Serra de la Llena, que veiem a la mateixa carretera, on som ara, i per sobre d’ella. (fotografia 3).

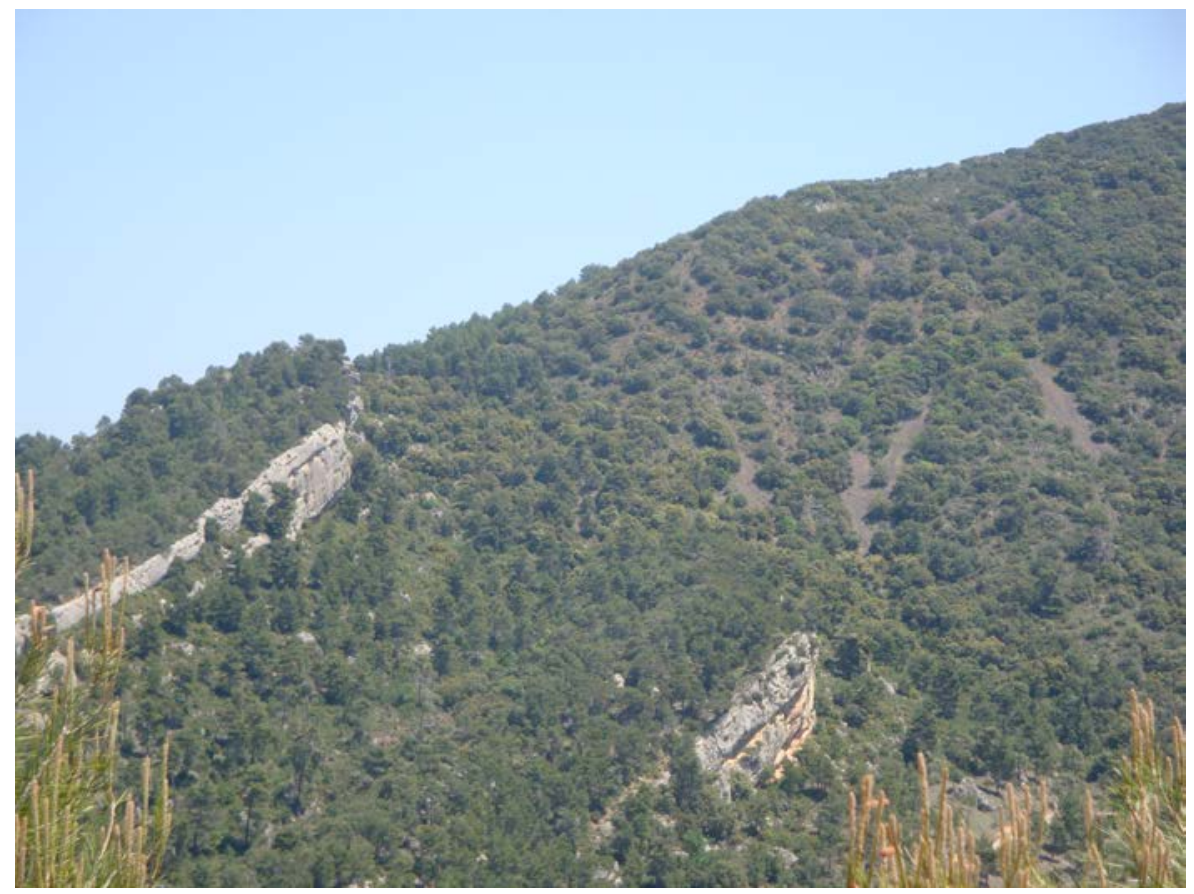

Fotografia 3. Falla del Pic de Saldes. A la dreta es veuen els materials paleozoics del Carbonífer (amb esquistos; mentre que a l'esquerra hi ha els nivells cenozoics de la formació Morera de Montsant, amb conglomerats calcaries i calcoutites ocres

Per altra banda, des d'aquest indret es pot observar una clara discordança entre els nivells basals i els nivells superiors de la Formació Montsant. Aquesta discordança, ja es farà molt més palesa cap a les immediacions del Km 12 


\subsection{Parada 3. CARRETERA DE VILANOVA DE PRADES A VIMBODÍ (TV - 7004), IMMEDIACIONS DE LA CRUİLLA D’ENTRADA A VALLCLARA, (terme municipal de Vallclara, comarca de la Conca de Barberà). (Full 417).}

Des de la parada anterior, cal continuar per la carretera local TV-7004, per tal d'apropar-nos cap a la població de Vallclara. En arribar-hi, caldrà sobrepassar-la lleugerament i poc després de deixar la cruillla d'on surt l'accés cap al poble, cal fer la present aturada, després de recórrer uns 3-4 Km, des de la parada anterior.

En tot aquest recorregut, inicialment hem trobat els materials de la Formació Montsant i després els de la Formació Morera de Montsant. Quasi immediatament, hem començat a trobar afloraments dels materials terrígens de la Formació Margalef, que són els que ara es troben en aquest indret on ara som. Aquí, entre ells, es fan palesos uns interessants i bons exemples de paleocanals, intercalats entre els gresos i les calcolutites gresenques de la formació acabada d'esmentar, integrant del Complex Al-luvial del Montsant.

\subsection{Parada 4. CARRETERA DE VILANOVA DE PRADES A VIMBODÍ (TV - 7005), IMMEDIACIONS DEL Km 19`7, (terme municipal de Vimbodí-Poblet, comarca de la Conca de Barberà). (Full 417).}

Després de realitzar la parada anterior, cal continuar cap a Vimbodí, per la carretera local TV 7004 (que ve d'Ulldemolins i que anem seguint des de Vilanova de Prades). En arribar a les immediacions del Km 19,7, caldrà fer una nova aturada. Així, des de la parada anterior, de la sortida de Vallclara. Haurem efectuat un recorregut molt proper als $4-5 \mathrm{Km}$, per tal d'arribar fins aquí.

En aquest recorregut, hem anat trobant afloraments dels materials cenozoics de la Formació Margalef (integrant del Complex Al-luvial del Montsant). Així, com a les altres aturades anteriors, estem situats dintre de la Depressió Geològica de l'Ebre (i més concretament, dintre de la seva Depressió Central).

En aquest indret de la parada, es troben aquests materials acabats d'esmentar, constituïts ara per nivells de gresos $\mathrm{i}$ de calcolutites ocres, amb freqüents paleocanals. Per d'altra banda, també es fan paleses nombrosos formacions de GUIX FIBRÒS. Aquest mineral, de neoformació, secundari, es troba reblint esquerdes i plans d'estratificació, entre els materials cenozoics acabats d'esmentar. (fotografia 4).. 


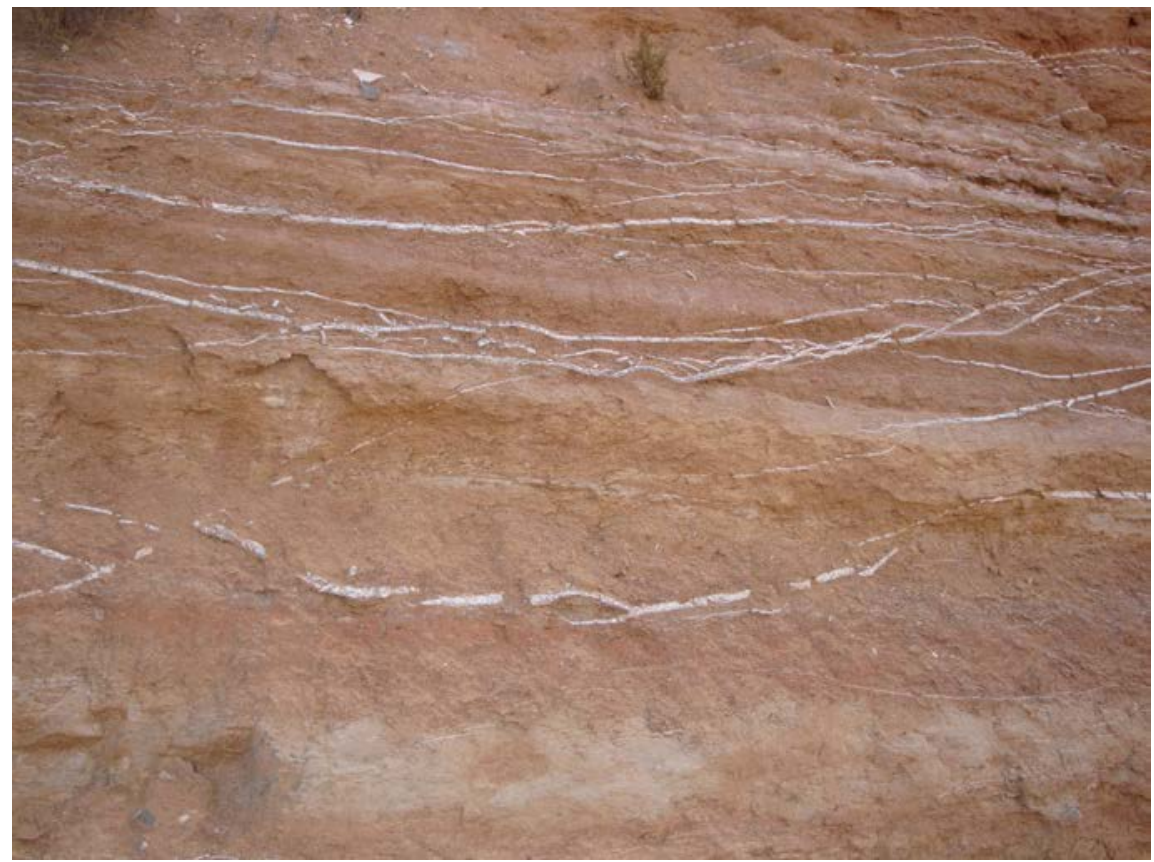

Fotografia 4. Aspecte del GUIX FIBRÓS, entre els materials cenozoics de la Formació Margalef. Immediacions de Vimbodí

\subsection{Parada 5 - CONDICIONAL. MINES DEL PIC DE SALDES O DEL MAS DEL FRANCÈS, (terme municipal de Vallclara, comarca de la Conca de Barberà). (Full 417).}

Després de la parada anterior, cal continuar per la carretera local TV-7004, anant cap a la localitat de Vimbodí. Poc abans d'arribar-hi, ens caldrà agafar la carretera que es dirigeix cap a Riudabella (la carretera local TV - 7003), des d'on agafarem el camí que ascendeix cap al Pic de Saldes, per on anirem cap a les Mines del Pic de Saldes (o del Mas del Francès). En arribar-hi, farem una nova aturada, després de recórrer uns $8 \mathrm{Km}$, des de la parada anterior.

En aquest recorregut, hem anat serpentejant entre els materials cenozoics de la Depressió Geològica de l'Ebre, i els paleozoics de la Serralada Prelitoral Catalana. Precisament, ara ens trobem en un aflorament d'aquests materials, els quals constitueixen el Pic de Saldes, on ara estem situats.

En aquest Iloc, hi ha una interessant mineralització filoniana de $\mathrm{Pb}-\mathrm{Zn}$, encaixada entre els materials esquistosos del Carbonífer. Entre els minerals presents, cal fer esment de la GALENA i de I'ESFALERITA.

Amb ells es troben diversos minerals d'alteració: GOETHITA (terrosa i limonítica), LEPIDOCROCITA (molt minoritària, d'aspecte com I'anterior), PIROLUSITA (dendrítica), CERUSSITA, ANGLESITA, PIROMORFITA, entre altres.

Per altra banda, cal fer esment de l'interessant patrimoni miner que hi ha en aquest lloc, el qual es troba exposat a perdre's. 
En aquest indret finalitza el recorregut de l'itinerari

\section{Bibliografia}

GUIMERÀ, J. et altri /1992).- Geologia (HI), Història Natural dels Països Catalans, Vol., 547 pag. Enciclopèdia Catalana, SA, Barcelona.

IGME (1973a).- Mapa Geológico de España (2a Sèrie). Explicación de las Hoja no 418 (Montblanc). Inst. Geol. Min. España. Minist. Indústria. Madrid.

IGME (1973b).- Mapa Geológico de España (2a Sèrie). Explicación de las Hoja nº 446 (Valls).. Inst. Geol. Min. España. Minist. Indústria. Madrid.

MATA-PERELLÓ, J.M. (1991).- Els Minerals de Catalunya. Institut d'Estudis Catalans. Arxius de la Secció de Ciències, T.XLVIII, 506 pag. Barcelona.

MATA-PERELLÓ, J.M. (1996).- Itinerari geològico - mineralògic per les comarques de les Garrigues, de la Conca de Barberà i de I'Alt Camp: des de Vinaixa a Vallclara, Poblet, Montblanc i a la Riba. Inèdit. 13 pàgines. Manresa.

MATA-PERELLÓ, J.M. (1997).- Recorregut de recerca geològica i mineralògica per les comarques de les Garrigues i de la Conca de Barberà. Inèdit, 14 pàg. Manresa.

MATA-PERELLÓ, J. M. (1999).- Recorregut de Recerca Geològica i Mineralògica per les comarques de les Garrigues, la Conca de Barberà i de l'Alt Camp: des de Vinaixa a Vimbodí, i des de la Pena a la Riba, Inèdit, 16 pag. Manresa.

MATA-PERELLÓ, J.M. (2000).- Recorregut de recerca geològica i mineralògica per les comarques de les Garrigues, la Conca de Barberà i del Priorat: des de Vinaixa a Poblet, i des de Vimbodí a Ulldemolins. Inèdit. 20 pàgines. Manresa.

MATA-PERELLÓ, J.M. (2001).- Recorregut de recerca geològica i mineralògica per les comarques de les Garrigues, de la Conca de Barberà i del Priorat: des de la Floresta a Poblet, i de Vilanova de Prades a Ulldemolins. Inèdit. 14 pàgines. Manresa.

MATA-PERELLÓ, J.M. (2002).- Recorregut de recerca geològica i mineralògica per les comarques del Priorat i de la Conca de Barberà: des de Porrera a Cornudella del Montsant, a Ulldemolins i a Vimbodí. Inèdit, 12 pag. Manresa.

MATA-PERELLÓ, J.M. (2004).- Recorregut de recerca geològica i mineralògica per les comarques del Priorat $\mathrm{i}$ de la Conca de Barberà: des de Cornudella del Montsant, a Ulldemolins, a Vallclara i a Vimbodí. Inèdit. 12 pag. Manresa.

MATA-PERELLÓ, J.M. (2011).- Recorregut de recerca geològica i mineralògica per les comarques del Baix Camp, del Priorat i de la Conca de Barberà: des de Prades al Coll Roig, a Ulldemolins, Vallclara i a Vimbodí. Inèdit. 8 pàgines. Manresa.

MATA-PERELLÓ, J.M. (2012a).- Recorregut de recerca geològica i mineralògica per les comarques de la Conca de Barberà, del Baix Camp i del Priorat: des de l'Espluga de Francolí a Prades, al Coll Roig, a Ulldemolins, Vallclara i a Vimbodí. Inèdit. 12 pàgines. Manresa. 
MATA-PERELLÓ, J.M. (2012b).- Recorregut de recerca geològica i mineralògica per les comarques del Priorat i de la Conca de Barberà: des d'Ulldemolins, a Vallclara i a Vimbodí. Inèdit. 12 pàgines. Manresa.

MATA-PERELLÓ, J.M. i COLLDEFORNS, B. (1996).- Itinerari geològic i mineralògic per la Conca de Barberà, pel Priorat i per la Ribera d’Ebre: des de Vimbodí a Ulldemolins i a Mora d’Ebre, Inèdit, 12 pag. Manresa.

MATA-PERELLÓ, J.M. i MONTANÉ GARCÍA, P. (1996).- Recorregut de recerca geològica i mineralògica per les comarques del Priorat y de la Conca de Barberà: des del Coll d'Albarca a Ulldemolins, a Vallclara i a Vimbodí. Inèdit. 10 pàgines. Manresa.

MELGAREJO,J.C. (1992).- Estudio geológico y metalogenético del paleozoico del sur de las Cordilleras Costeras Catalanas. Memórias dels Instituto Tecnológico y Geo-Minero de España, tomo 103, 605 pag. Madrid.

RIBA, O. et altri (1976).- Geografia Física dels Països Catalans. Edit. Ketres, 254 pàgines. Barcelona. 